\title{
IMPACT OF DYNAMICAL THERMAL BEHAVIOUR OF EXTERNAL CONSTRUCTIONS ON INDOOR TEMPERATURE IN WARM LOCATIONS: THE CASE OF SAO CARLOS, BRAZIL
}

\author{
UDO DIETRICH \\ REAP Research Group (Resource Efficiency in Architecture and Planning), HafenCity University Hamburg, \\ Germany
}

\begin{abstract}
In warm locations the effect that (strong) solar radiation is first absorbed on the outer surface, then transferred through the construction materials and finally arrives at the inner surface heating it up may be remarkable. The corresponding physical models describe this dynamical thermal behaviour, which is described by the quantities decrement factor (also known as temperature-amplitude-damping) and delay. There are two measures to reduce negative effects; thermal insulation and thermal inertness (mass).

The paper investigates this effect in the warm and humid climate of Sao Carlos, Brazil. A typical living room is defined and both traditional and contemporary external wall constructions are proposed and assessed in regard to their thermal behaviour.

The corresponding local standards NBR 15575 and 15220 give thresholds for stationary and dynamical physical behaviour. The proposed constructions were assessed, and it was found they fulfil all the obligatory NBR 15575 standards (U-value and thermal storage mass) but not the wider recommendations of NBR 15220. All constructions were also assessed with the European standard ISO 13786 that describes the dynamical physical behaviour precisely, whereas the Brazilian standards use approximate formulas.

The selected room was investigated with the transient simulation software Primero-Comfort and the resulting indoor operative temperatures were assessed. Traditional constructions (brick) show very good values, whereas contemporary constructions (concrete slab, hollow concrete element) do not. The differences in indoor operative temperature lie in the range of two degrees, especially for the daily peaks.

Furthermore, wood-based constructions were proposed and simulated. The room already behaved better with the simplest construction (two sheets of plywood) than contemporary constructions. A filling with $5 \mathrm{~cm}$ thermal insulation leads to very good values.

Finally, recommendations for the currently used standards are given. Only the quantities of ISO 13786 correlate well with the results; it describes the physical behaviour well and should be used to derive thresholds. NBR 15220 describes the decrement delay in satisfying correlation with the results but fails in the corresponding quantity for the decrement factor. Additionally, the obligatory NBR 15575 excludes light wood-based constructions even though such constructions behave well in the regarded climate. Both standards should be adapted.

Key words: contemporary constructions, dynamical thermal behaviour of external constructions, indoor operable temperature, standards for thermal quantities of constructions, traditional constructions, transient simulation, warm climates, wood-based constructions.
\end{abstract}

\section{INTRODUCTION}

A construction separates the interior of a building from the exterior. If the temperatures, $T_{\mathrm{e}}$ and $T_{\mathrm{i}}$, are not identical, a heat flux density $\Psi\left[\mathrm{W} / \mathrm{m}^{2}\right]$ is caused through the construction that tries to balance both temperatures.

Most interesting for the assessment of comfort is the size of that heat flux, especially on the internal surface. If it is oriented from interior to exterior, it cools down the building (winter case), whereas if it is oriented from exterior to interior, it heats up the building. 
In climates with long heating or cooling seasons where $T_{\mathrm{e}}$ is permanently out of the comfort range, the main task of the construction is to reduce the heat flux as much as possible; a very good (low) U-value is the adequate solution. The U-value of a construction describes its thermal quality under stationary conditions; here $\Psi$ is constant in amount and direction through the whole construction.

$$
\Psi=\mathrm{U} *\left(T_{\mathrm{i}}-T_{\mathrm{e}}\right) . \quad\left[\mathrm{W} / \mathrm{m}^{2}\right]
$$

$\mathrm{U}$ is the reciprocal of the thermal resistance $\mathrm{RT}\left[\mathrm{m}^{2} \mathrm{~K} / \mathrm{W}\right]$ of the whole construction; RT is the sum of all single resistances (one per layer plus internal and external heat transfer resistance $R s_{\mathrm{i}}$ and $R s_{\mathrm{e}}$, respectively). The bigger the thermal resistance RT, the smaller the heat flux.

$$
\mathrm{U}=1 / \mathrm{RT} . \quad\left[\mathrm{W} / \mathrm{m}^{2} \mathrm{~K}\right]
$$

Much more complex is the case that $T_{\mathrm{e}}$ cannot be assumed as constant, because it changes in time. The most interesting case is a 24 -hour swing in $T_{\mathrm{e}}$ simply caused by outdoor ambient temperature and solar radiation on the external surface. The behaviour of the construction becomes dynamical; due to the swing, the heat flux is no longer constant through the construction and can have different directions (inwards as well as outwards) in different ranges of the construction. The resulting heat flux on the internal surface of the construction determines if the room is heated up/cooled down and also if it delivers comfort/discomfort.

Because most of the standards, literature, products, etc. are coming from countries with moderate to cold climates, the entire world looks at them and is thus sensitive to U-values only. Contemporary building technologies are based on cost optimization and not on the optimization of user's comfort, the separation into investors and (anonymous) users leads to constructions that do not behave optimally in the physical sense. It is well known from both experience and literature that contemporary buildings heat up remarkably stronger (especially in the last floor under the roof) than traditional ones. The effect of solar heat that is absorbed by the external surface and transferred to the interior surface very strongly and thus finally heating up the room is widely underestimated. National standards in hot countries do not widely prescribe minimal qualities in that field.

This article gives an overview of existing calculation methods (Section 2), recommendations for optimal dynamical thermal quantities of constructions (Section 3), applies them to a location in Brazil with the assessment of traditional and contemporary constructions (Section 4), presents the results of dynamical simulations of a typical living room with the impact of different external constructions on thermal comfort and cooling demand (Section 5) and gives a final discussion of the results with recommendations for future standards (Section 6).

\section{EXISTING CALCULATION METHODS FOR DYNAMICAL THERMAL QUANTITIES OF CONSTRUCTIONS}

\subsection{Definitions}

The main quantities of dynamical thermal behaviour of constructions are decrement factor f and decrement delay (time lag). To differentiate stationary from dynamical quantities, the dynamic quantities are underlined from here on.

Because of the swinging outdoor temperature $T_{\mathrm{e}}$ (or the temperature on the external surface $T s_{\mathrm{e}}$ caused by solar radiation), the heat flux in the construction changes direction with each swing and the material with its thermal storage mass has to be heated or cooled, respectively. 


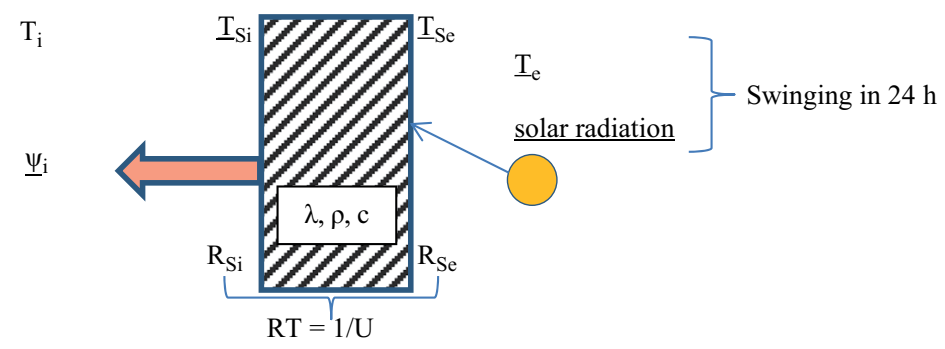

Figure 1: An external wall under swinging outdoor temperature and solar radiation. The resulting heat transfer to the inner surface is reduced by the dynamic thermal quantities of the construction and described by standard ISO 13786.

This slows down the heat transfer process and is described by the decrement. Besides the thermal conductivity $\lambda[\mathrm{W} / \mathrm{mK}]$, now density $\rho\left[\mathrm{kg} / \mathrm{m}^{3}\right]$ and heat capacity $[\mathrm{Ws} / \mathrm{kg} \mathrm{K}]$ of the materials determine the supplementary physical behaviour.

The decrement factor $\mathrm{f}$ is defined as (Fig. 1):

$$
\mathrm{f}=\Psi_{\mathrm{i}} / T_{\mathrm{e}} *(1 / \mathrm{U})
$$

It is always $\mathrm{f} \leq 1$. The term $\Psi_{\mathrm{i}} / T_{\mathrm{e}}$ can be interpreted as a dynamical $\mathrm{U}$-value because of the effects of thermal storage mass smaller than the stationary $U$-value. The reciprocal $1 / f$ is an easy to read value always $\geq 1$ and it shows how often the stationary U-value is bigger than the dynamical U-value. But even then the decrement is difficult to understand. For practical use, it would be much more comprehensive to have information about the temperature damping (attenuation) of the amplitudes of the temperatures $T_{\mathrm{e}}$ and $T s_{\mathrm{i}}$ (TAD: TemperatureAmplitude-Damping):

$$
\text { TAD = amplitude of } T_{\mathrm{e}} / \text { amplitude of } T s_{\mathrm{i}} .
$$

This would immediately show the temperature on the internal side of the construction. The corresponding heat flux density $\Psi_{\mathrm{i}}$ is determined only by the internal heat transfer resistance $R s_{\mathrm{i}}$.

$$
\Psi_{\mathrm{i}}=1 / R s_{\mathrm{i}} * T s_{\mathrm{i}}
$$

Combining eqns (2) to (5) yields:

$$
\mathrm{TAD}=1 / \mathrm{f} * \mathrm{RT} / R s_{\mathrm{i}}
$$

The time lag between the amplitudes of both waves $T_{\mathrm{e}}$ and $T_{\mathrm{i}}$ is the decrement delay.

\subsection{Existing calculation methods}

The dynamical behaviour of constructions is described in the standard ISO 13786; with the main results being decrement factor $f$ and decrement delay. Because of the changing directions of the heat flux and the processes of storing heat, the mathematical description uses complex figures and matrices to describe the reduction in the heat transfer that goes through the whole construction. The mathematical model is complex but can be handled in a standard spreadsheet where supplementary TAD (eqn (6)) can be calculated (Fig. 2). 


\begin{tabular}{|c|c|c|c|c|c|c|c|c|c|}
\hline \multicolumn{10}{|c|}{ Stationary and dynamical quantities of multi-layered constructions (EN ISO 13786) } \\
\hline \multicolumn{10}{|c|}{ RESULTS } \\
\hline \multicolumn{2}{|c|}{ stationary U-value } & & Uo & 2.39 & $\mathrm{~W} / \mathrm{m}^{2} \mathrm{~K}$ & \multicolumn{2}{|c|}{ TAD stationary } & 3.23 & 1/(Rsi/RT) \\
\hline \multicolumn{2}{|c|}{ decrement factor } & & $f$ & 0.802 & & \multicolumn{4}{|c|}{ temperature-amplitude-damping TAD } \\
\hline & decrement & & $1 / f$ & 1.25 & & \multicolumn{2}{|c|}{ TAD dynamical } & 4.02 & \\
\hline & & & & & & & & \multicolumn{2}{|c|}{ (TAD stationary/f) } \\
\hline \multicolumn{10}{|l|}{ time lag } \\
\hline & decrement delay & & $\Delta t_{f}$ & 3.49 & h & & & & \\
\hline & & & plus 24 & 27.49 & $\mathrm{~h}$ & \multicolumn{4}{|c|}{ may be for extremely thick and massive } \\
\hline & & & & & & \multicolumn{2}{|c|}{ constructions } & & \\
\hline \multicolumn{10}{|c|}{ INPUT - Up to 10 layers } \\
\hline & & \multicolumn{5}{|c|}{ non-existent layers with $\mathrm{d}=0$ or delete all values! } & & & \\
\hline & & {$[\mathrm{m}]$} & {$[\mathrm{W} / \mathrm{mK}]$} & {$\left[\mathrm{kg} / \mathrm{m}^{3}\right]$} & {$[\mathrm{Ws} / \mathrm{kgK}]$} & {$\left[\mathrm{m}^{2} \mathrm{~K} / \mathrm{W}\right]$} & {$[\mathrm{m}]$} & {$[-]$} & \\
\hline layer & name & d & $\lambda$ & $\rho$ & c & $\mathbf{R}$ & $\xi$ & $\delta$ & \\
\hline internal & & & & & & 0.13 & & & \\
\hline 1 & plaster & 0.025 & 1.150 & 1950 & 840 & 0.022 & 0.139 & 0.180 & \\
\hline 2 & concrete & 0.023 & 1.750 & 2300 & 1000 & 0.013 & 0.145 & 0.157 & \\
\hline 3 & air gap & 0.045 & 0.248 & 1.25 & 1000 & 0.180 & 2.336 & 0.019 & \\
\hline 4 & concrete & 0.023 & 1.750 & 2300 & 1000 & 0.013 & 0.145 & 0.157 & \\
\hline 5 & plaster & 0.025 & 1.150 & 1950 & 840 & 0.022 & 0.139 & 0.180 & \\
\hline 6 & & & & & & 0.000 & 0.000 & 0.000 & \\
\hline 7 & & & & & & 0.000 & 0.000 & 0.000 & \\
\hline 8 & & & & & & 0.000 & 0.000 & 0.000 & \\
\hline 9 & & & & & & 0.000 & 0.000 & 0.000 & \\
\hline 10 & & & & & & 0.000 & 0.000 & 0.000 & \\
\hline \multirow[t]{5}{*}{ external } & & & & & & 0.04 & & & \\
\hline & & d_ges & & & & R_T & & & \\
\hline & & 0.140 & & & & $0 . \overline{249}$ & & & \\
\hline & & & & & & & \multicolumn{3}{|c|}{ periodic penetration depth } \\
\hline & & & & & & & & ratio $d / \delta$ & \\
\hline
\end{tabular}

Figure 2: Spreadsheet with calculation according to ISO 13786 of decrement factor, decrement delay and TAD for constructions with up to 10 layers [3].

The British Concrete Centre also offers a spreadsheet tool [1] that calculates decrement factor and delay, but not TAD.

An approximation for TAD and decrement delay with easy to handle formulas is given in [2]. A comparison with the detailed calculation according to ISO 13786 shows a surprisingly good accordance; therefore, the formulas can be used for quick estimations.

Figure 3 shows a representative overview of the dynamical behaviour of an external construction. To clarify the graph, a single brick layer was chosen. The graph shows the temperatures on the inner surface with increasing thickness (the graph does NOT show the temperatures inside of the construction!). Dashed lines show the corridors determined by stationary behaviour (U-value alone) as well as dynamical behaviour (U-value and 1/f, see eqns (6) and (2)), with real temperatures lying inside them. It can clearly be seen that the decrement (effect of dynamical behaviour through storing processes that slows down the heat transfer) 


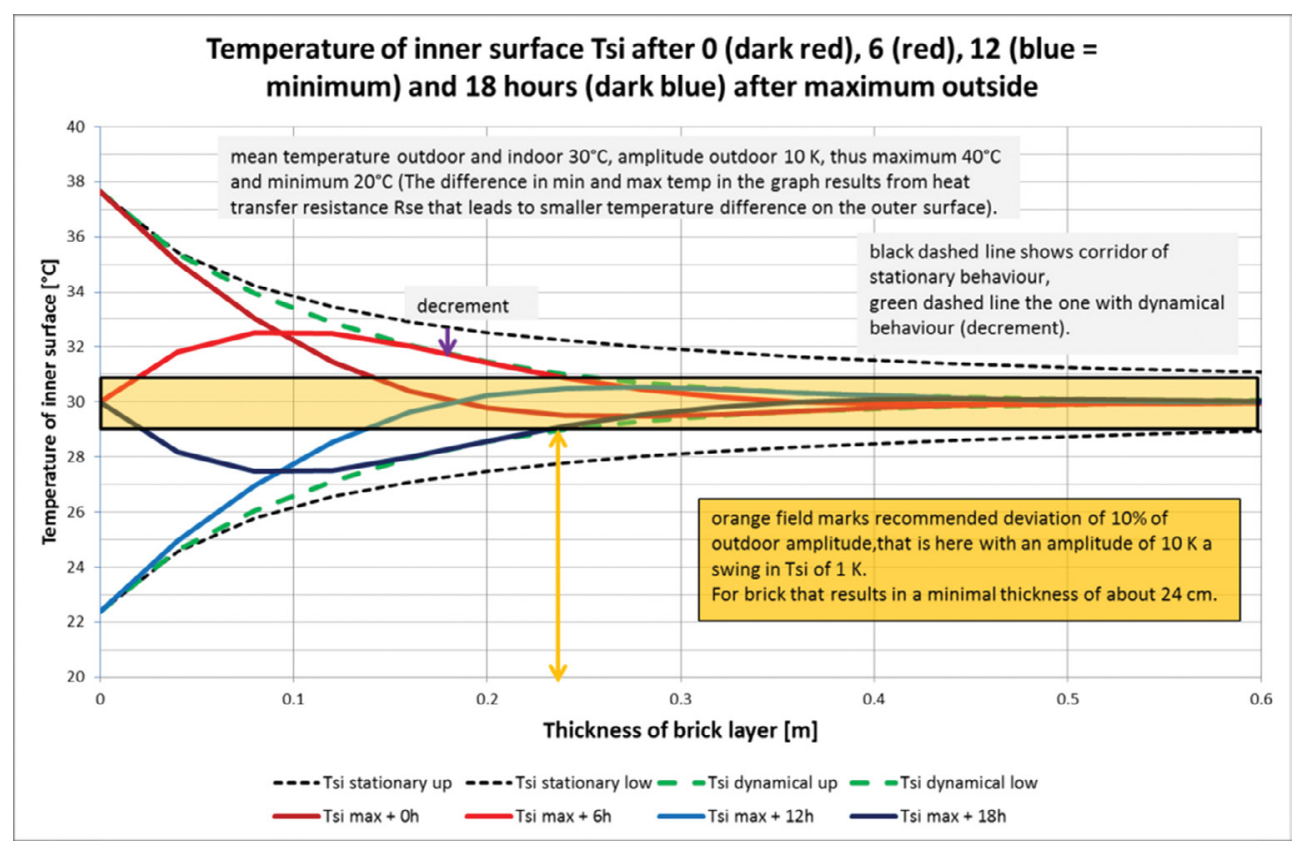

Figure 3: The graph shows the temperatures on the inner surface for a brick wall with increasing thickness. Dashed lines show the corridors determined by stationary behaviour as well as dynamical behaviour. Real temperatures lie inside of these corridors; they are included with coloured lines for a given time after the peak $(0$, 6,12 and 18 hours).

increases rapidly with increasing thickness of the wall. Examples for real temperatures are shown with coloured lines for a given time after the peak $(0,6,12$ and 18 hours).

The recommended range with $\mathrm{TAD} \geq 10$ (Section 3 ) is shown with the orange horizontal rectangle, for the brick wall a minimal thickness of about $24 \mathrm{~cm}$ fulfils this request.

The recommended range with $\mathrm{TAD} \geq 10$ (see Section 3 ) is shown with the orange horizontal rectangle, for the brick wall a minimal thickness of about $24 \mathrm{~cm}$ fulfils this request.

\section{RECOMMENDATIONS FOR OPTIMAL VALUES OF 1/f AND TAD}

The main objective is to avoid too strong of a heat transfer from the exterior to the interior during hot periods that are potentially due to high temperatures on the external side of the construction. But the worst case here is solar radiation that strikes the external surface of the construction, thereby heating it up. To assess this effect, the external heat transfer resistance $R s_{\mathrm{e}}$ should be set to zero in the calculation of decrement and TAD (that corresponds to the assumption that the external surface is heated directly by solar radiation). Depending on material and colour, temperatures up to $65^{\circ} \mathrm{C}$ are possible. With an assumed outdoor temperature of $25^{\circ} \mathrm{C}$, the temperature $T s_{\mathrm{e}}$ would swing over 40 degrees, with amplitude of 20 degrees around the mean value of $45^{\circ} \mathrm{C}$. Which part of those 20 degrees outside may still arrive on the inner surface? There are two criteria to regard:

- Thermal comfort: The temperature on the inner surface shall not differ more than 2 to 3 degrees from the air temperature.

- Heat transfer and risk of overheating. For stationary conditions the heat flux is: 


$$
\Psi=1 / R s_{\mathrm{i}} *\left(T s_{\mathrm{i}}-T_{\mathrm{i}}\right) . \quad\left[\mathrm{W} / \mathrm{m}^{2} \mathrm{~K}\right]
$$

With the standard value $R s_{\mathrm{i}}=0.13 \mathrm{~m}^{2} \mathrm{~K} / \mathrm{W}$ results a heat transfer of $7.7 \mathrm{~W}$ per square meter of the construction and degree temperature difference. Rooms at a building's corner or under the roof have areas of external constructions in the same range as the area of usage, leading to a remarkable amount of heat transfer. As a consequence, the temperature difference $\left(T s_{\mathrm{i}}-T_{\mathrm{i}}\right)$ shall be limited to 1 to 2 degrees.

Both aspects would be fulfilled if TAD is bigger than $20 / 2=10$, better TAD $\geq 15$.

$$
\begin{aligned}
& \text { TAD }<5 \\
& \text { TAD }<10 \\
& \text { TAD }<15 \\
& \text { TAD } \geq 15
\end{aligned}
$$

$$
\begin{aligned}
& \text { very critical, strong risk of overheating } \\
& \text { critical, risk of overheating } \\
& \text { less critical, but contributes still to overheating } \\
& \text { recommended }
\end{aligned}
$$

High TAD values can be reached in two different ways and a combination of both (TAD is the product of a) and $b)$ ):

a) A small U-value (thermal insulation).

Equation (6) shows that TAD $=10$ is reached even for a weightless construction (and thus no decrement and $\mathrm{f}=1$ ) with $\mathrm{RT}=10 R s_{\mathrm{i}}$. With the standard value $R s_{\mathrm{i}}=0.13 \mathrm{~m}^{2} \mathrm{~K} / \mathrm{W}$ for a wall results $\mathrm{RT}=1.3 \mathrm{~m}^{2} \mathrm{~K} / \mathrm{W}$ or with $\mathrm{U}^{1}=1 / \mathrm{RT}$ a $\mathrm{U}$-value of $0.77 \mathrm{~W} / \mathrm{m}^{2} \mathrm{~K}$. The value $\mathrm{RT}$ $=1.3 \mathrm{~m}^{2} \mathrm{~K} / \mathrm{W}$ is reached with thermal insulation of, at minimum, $4 \mathrm{~cm}(\lambda=0.035 \mathrm{~W} / \mathrm{mK}$, $\left.R s_{\mathrm{e}}=0.04 \mathrm{~m}^{2} \mathrm{~K} / \mathrm{W}\right)$. For contemporary constructions in cold and moderate climates that is given all the time but constructions in hot climates generally do not have insulation.

b) A big decrement $1 / \mathrm{f}$ (heavy materials with big thermal storage mass).

If TAD is in a critical range, the decrement delay also becomes important. If the time lag is very short (less than 6 hours), then the heat is already transferred during the day, additionally heating up the room. A longer decrement delay of about 8 to 12 hours would shift the transfer of heat to the night hours with the possibility to ventilate it with cooler night air. For locations with strong temperature changes between day and night (hot and dry), the late heat transfer might also be a very welcome help to heat the room.

\section{APPLICATION: A REPRESENTATIVE ROOM OF AN APARTMENT IN A HOT AND HUMID CLIMATE IN SAO CARLOS (BRAZIL), TRADITIONAL AND CONTEMPORARY CONSTRUCTIONS AND THEIR ASSESSMENT ACCORDING TO EXISTING STANDARDS}

Sao Carlos is a city in the south of Brazil, about $230 \mathrm{~km}$ northwest of Sao Paulo. According to the Koeppen-Geiger classification, its climate is $\mathrm{Cfa}$, a temperate climate with warm and humid summers. Because of its high elevation, daily temperatures lie predominantly in the comfortable range between $25^{\circ} \mathrm{C}$ and $30^{\circ} \mathrm{C}$ and are rarely higher.

\subsection{Existing standards}

Several standards [4] regulate the thermal quantities of constructions in Brazil. NBR 15220 gives several recommendations for the stationary and dynamical thermal quantities of constructions and the corresponding formulas for their calculation. Besides the commonly known $\mathrm{U}$-value $\left[\mathrm{W} / \mathrm{m}^{2} \mathrm{~K}\right]$, these are 
- The thermal capacity $\mathrm{C}_{\mathrm{T}}\left[\mathrm{kJ} / \mathrm{m}^{2} \mathrm{~K}\right]$. It describes the whole capacity of all their layers and does not refer to dynamic processes where the internal layers dominate.

- The time lag $\phi[\mathrm{h}]$ and the solar factor $\mathrm{FS}_{0}[\%]$. They describe the dynamical thermal behaviour but use approximate formulas and do not correspond to ISO 13786. Especially the solar factor $\mathrm{FS}_{0}$ contains only the absorption of solar radiation on the external surface of the construction and does not regard the following weakening of the transferred thermal energy by effects of insulation and thermal inertness (like it is done in ISO 13786).

NBR 15220 divides Brazil into eight different climate zones; Sao Carlos is located in zone 4. Recommendations are

- A window size (more precisely, the size of opening for natural ventilation) between $15 \%$ and $25 \%$ of area of usage.

- A heavy wall construction with $\mathrm{U} \leq 2.2 \mathrm{~W} / \mathrm{m}^{2} \mathrm{~K}$, time lag $\phi \geq 6.5$ hours and solar factor $\mathrm{FS}_{0} \leq 3.5 \%$

NBR 15575 is obligatory and requires for external walls in zone 4 a $\mathrm{U}$-value $\leq 3.7 \mathrm{~W} / \mathrm{m}^{2} \mathrm{~K}$ (bright surfaces, absorptance of solar radiation below 60\%) and a thermal capacity $\mathrm{C}_{\mathrm{T}}$ of $>=$ $130 \mathrm{~kJ} / \mathrm{m}^{2} \mathrm{~K}$.

\subsection{Design of investigated room}

A typical room of an apartment has the dimensions $\mathrm{W}=\mathrm{H}=3 \mathrm{~m}$ and $\mathrm{D}=5 \mathrm{~m}$. The investigation shall show the impact of dynamical thermal properties of the wall construction, thus a room in a building's corner with two external walls facing north (façade with window) and west was chosen (Fig. 4). These external walls have a bright surface with an absorptance of $33 \%$.

Following NBR 15220, the window (ventilation opening) size is set to $15 \%$ of area of usage and an assumed $1.5 \times 1.5 \mathrm{~m}$ with single glazing and a wooden frame.

In preliminary simulations, it was found that an overhang with a depth of $1.5 \mathrm{~m}$ creates a maximum of shade on the window during the summer months.

The room is used from 6 am to midnight, with standard assumptions for internal heat gains. Artificial light is only used if there is not enough daylight in the room. Cross-ventilation is assumed as possible 24 hours a day (which delivers a request for the corresponding floor plan!).

Now, different combinations of the construction of external and internal walls and intermediate ceiling and floor corresponding to traditional and contemporary architecture are investigated for their impact on indoor operative temperature.

4.3 Traditional and contemporary constructions and assessment of their dynamical thermal properties according to Brazilian NBR15220/15575 and ISO 13786

\subsubsection{Traditional architecture}

The constructions were based on local materials. External and partly internal walls were load bearing, ceiling and floor wood constructions. For external walls, adobe or bricks were used. Here, a representative $36 \mathrm{~cm}$ brick wall with internal and external plaster is selected (Table 1); the separating internal walls are assumed as medium massive (e.g. brick, limestone). 


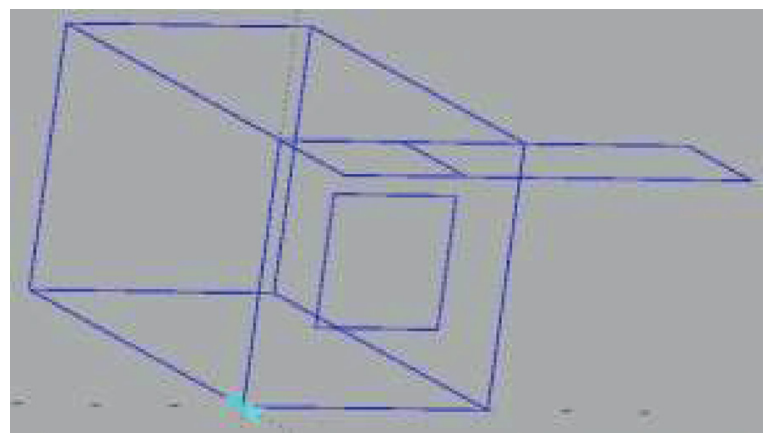

Figure 4: Geometry and orientation of investigated typical apartment room; the north-oriented facade receives most of its solar radiation during summer.

Table 1: Quantities of traditional external wall TRAD W and the fictive construction NBR W (that narrowly fulfils NBR 15220) and their assessment according to ISO 13786 and NBR 15575/15220.

\begin{tabular}{|c|c|c|c|c|c|c|}
\hline Layer & Name & Thickness & $\begin{array}{l}\text { Resistance } \\
\text { Air Gap }\end{array}$ & $\begin{array}{l}\text { Conduc- } \\
\text { tivity }\end{array}$ & Density & Capacity \\
\hline & & $\mathrm{D}$ & $\mathrm{Rg}$ & $\lambda$ & $\rho$ & $\mathrm{C}_{\mathrm{T}}$ \\
\hline TRAD W & & {$[\mathrm{m}]$} & {$\left[\mathrm{m}^{2} \mathrm{~K} / \mathrm{W}\right]$} & {$[\mathrm{W} / \mathrm{mK}]$} & {$\left[\mathrm{kg} / \mathrm{m}^{3}\right]$} & {$[\mathrm{KJ} / \mathrm{kg} \mathrm{K}]$} \\
\hline 1 & Plaster & 0.025 & & 1.15 & 1,950 & 0.84 \\
\hline 2 & Brick & 0.36 & & 0.58 & 1,400 & 1 \\
\hline \multirow[t]{5}{*}{3} & Plaster & 0.025 & & 1.15 & 1,950 & 0.84 \\
\hline & \multicolumn{6}{|c|}{ Quantities of construction and assessment (y/n) } \\
\hline & $\begin{array}{l}\text { NBR } \\
15220\end{array}$ & ISO 13786 & & NBR 152 & & NBR 15575 \\
\hline & $\mathrm{U}$ & Time lag & TAD & $\phi$ & $\mathrm{FS}_{0}$ & $\mathrm{C}_{\mathrm{T}}$ \\
\hline & {$\left[\mathrm{W} / \mathrm{m}^{2} \mathrm{~K}\right]$} & {$[\mathrm{h}]$} & - & {$[\mathrm{h}]$} & {$[\%]$} & {$\left[\mathrm{KJ} / \mathrm{m}^{2} \mathrm{~K}\right]$} \\
\hline Request & $\leq 2.2$ & - & $\geq 15$ & $\geq 6.5$ & $\leq 3.5$ & $\geq 130$ \\
\hline TRAD W & 1.20 & 13.6 & 45.4 & 11.6 & 1.6 & 586 \\
\hline $\mathrm{Y} / \mathrm{N}$ & Y & $\mathrm{Y}$ & $\mathrm{Y}$ & $\mathrm{Y}$ & $\mathrm{Y}$ & $\mathrm{Y}$ \\
\hline NBR W & 1.9 & 7.2 & 8.5 & 6.5 & 2.5 & 337 \\
\hline $\mathrm{Y} / \mathrm{N}$ & $\mathrm{Y}$ & - & $\mathrm{N}$ & $\mathrm{Y}$ & $\mathrm{Y}$ & $\mathrm{Y}$ \\
\hline
\end{tabular}

To check the recommendations of NBR 15220, the thickness of the brick layer was reduced until the first threshold of that standard was reached. This was the case with an $18.2 \mathrm{~cm}$ brick instead of $36 \mathrm{~cm}$, and here the time lag limit of 6.5 hours is reached (construction NBR W).

\subsubsection{Contemporary architecture}

In contemporary architecture (steel-) concrete constructions are common. They deliver a loadbearing system in the interior of the building that, in principle, allows for the replacement of 
Table 2: Quantities of contemporary external wall CON REF and CON W (10 cm concrete slab, plaster on both sides) and their assessment according to ISO 13786 and NBR 15575/15220. All material quantities are taken from NBR 15220.

\begin{tabular}{|c|c|c|c|c|c|c|}
\hline Layer & Name & Thickness & $\begin{array}{l}\text { Resistance } \\
\text { Air Gap }\end{array}$ & $\begin{array}{l}\text { Conduc- } \\
\text { tivity }\end{array}$ & Density & Capacity \\
\hline & & $\mathrm{D}$ & $\mathrm{Rg}$ & $\lambda$ & $\rho$ & $\mathrm{C}_{\mathrm{T}}$ \\
\hline CON REF & & {$[\mathrm{m}]$} & {$\left[\mathrm{m}^{2} \mathrm{~K} / \mathrm{W}\right]$} & {$[\mathrm{W} / \mathrm{mK}]$} & {$\left[\mathrm{kg} / \mathrm{m}^{3}\right]$} & {$[\mathrm{KJ} / \mathrm{kg} \mathrm{K}]$} \\
\hline 1 & Plaster & 0.025 & & 1.15 & 1,950 & 0.84 \\
\hline 2 & Concrete & 0.0227 & & 1.75 & 2,300 & 1 \\
\hline 3 & Air gap & 0.0446 & 0.18 & 0.248 & 1.25 & 1 \\
\hline 4 & Concrete & 0.0227 & & 1.75 & 2,300 & 1 \\
\hline \multirow[t]{5}{*}{5} & Plaster & 0.025 & & 1.15 & 1,950 & 0.84 \\
\hline & \multicolumn{6}{|c|}{ Quantities of construction and assessment (Y/N) } \\
\hline & $\begin{array}{l}\text { NBR } \\
15220 \\
\end{array}$ & \multicolumn{2}{|c|}{ ISO 13786} & \multicolumn{2}{|c|}{ NBR 15220} & NBR 15575 \\
\hline & $\mathrm{U}$ & Time lag & TAD & $\phi$ & $\mathrm{FS}_{0}$ & $\mathrm{C}_{\mathrm{T}}$ \\
\hline & {$\left[\mathrm{W} / \mathrm{m}^{2} \mathrm{~K}\right]$} & {$[\mathrm{h}]$} & - & {$[\mathrm{h}]$} & {$[\%]$} & {$\left[\mathrm{KJ} / \mathrm{m}^{2} \mathrm{~K}\right]$} \\
\hline Request & $\leq 2.2$ & - & $\geq 15$ & $\geq 6.5$ & $\leq 3.5$ & $\geq 130$ \\
\hline CON REF & 2.38 & 3.5 & 4.0 & 5.31 & 3.1 & 273 \\
\hline $\mathrm{Y} / \mathrm{N}$ & $\mathrm{N}$ (early) & $\mathrm{N}$ & $\mathrm{N}$ & $\mathrm{N}$ (early) & $\mathrm{Y}$ & $\mathrm{Y}$ \\
\hline CON W & 3.7 & 4.1 & 3.1 & 3.6 & 4.9 & 312 \\
\hline $\mathrm{Y} / \mathrm{N}$ & $\mathrm{N}$ & - & $\mathrm{N}$ & $\mathrm{N}$ & $\mathrm{N}$ & $\mathrm{Y}$ \\
\hline
\end{tabular}

external wall constructions with any fill that provides minimal protection. Alternatively, the external wall can be a continuation of the internal concrete slab.

The most simple (and thin) wall, CON W, is composed of a $10 \mathrm{~cm}$ concrete slab with 2.5 $\mathrm{cm}$ plaster on both sides. An improved version, CON REF (which is widely used and can be regarded as a reference), uses hollow concrete elements with an air gap in the centre and plaster on both sides.

The wall, CON REF (hollow concrete elements), does not fulfil all recommended criteria of NBR 15220 but is near the limits, whereas the recommendations of ISO 13786 are clearly not reached (Table 2). The wall CON W (concrete slab) does not fulfil any of the limits of NBR 15220 as well as ISO 13786, but it just reaches the obligatory U-value NBR 15575 and is thus permitted to use in construction (and it is in reality).

As an alternative to contemporary concrete constructions, in [5] wood-based constructions (WBC) are proposed as external walls are proposed. It is always a simple composition (Table 3) with two internal and external sheets of plywood and as filling and air gap (construction WBC $\mathrm{W} 1$ ) or as improvement thermal insulation (mineral fibre, $0.065 \mathrm{~W} / \mathrm{mK}$, construction WBC W 2). All these materials are currently easily available on-site.

Because of the improved U-value, both WBC fulfil here the recommendations of NBR 15220. Also, the improved construction WBC W 2 nearly meets the dynamical behaviour requirement for NBR 15220 and ISO 13786. But both WBC do not fulfil the obligatory NBR 15575 , because of the lack of thermal mass $\left(C_{T}\right.$ far below threshold $)$. 
Table 3: Quantities of possible contemporary or future wood-based external wall constructions WBC W 2 and WBC W 1 (air gap instead of mineral fibre) and their assessment according to ISO 13786 and NBR 15575/15220. All material quantities are taken from NBR 15220.

\begin{tabular}{|c|c|c|c|c|c|c|}
\hline LAYER & Name & Thickness & $\begin{array}{l}\text { Resistance } \\
\text { Air Gap }\end{array}$ & $\begin{array}{l}\text { Conduc- } \\
\text { tivity }\end{array}$ & Density & Capacity \\
\hline & & $\mathrm{D}$ & $\mathrm{Rg}$ & $\lambda$ & $\rho$ & $\mathrm{C}_{\mathrm{T}}$ \\
\hline WBC W 2 & & {$[\mathrm{~m}]$} & {$\left[\mathrm{m}^{2} \mathrm{~K} / \mathrm{W}\right]$} & {$[\mathrm{W} / \mathrm{mK}]$} & {$\left[\mathrm{kg} / \mathrm{m}^{3}\right]$} & {$[\mathrm{KJ} / \mathrm{kg} \mathrm{K}]$} \\
\hline 1 & Plywood & 0.022 & & 0.12 & 400 & 2.3 \\
\hline 3 & $\begin{array}{l}\text { Mineral } \\
\text { fibre }\end{array}$ & 0.05 & & 0.065 & 533 & 1.8 \\
\hline \multirow[t]{5}{*}{4} & Plywood & 0.022 & & 0.12 & 400 & 2.3 \\
\hline & \multicolumn{6}{|c|}{ Quantities of construction and assessment (Y/N) } \\
\hline & NBR 15220 & ISO 13786 & & NBR 1522 & & NBR 15575 \\
\hline & $\mathrm{U}$ & Time lag & TAD & $\phi$ & $\mathrm{FS}_{0}$ & $\mathrm{C}_{\mathrm{T}}$ \\
\hline & {$\left[\mathrm{W} / \mathrm{m}^{2} \mathrm{~K}\right]$} & [h] & - & [h] & {$[\%]$} & {$\left[\mathrm{KJ} / \mathrm{m}^{2} \mathrm{~K}\right]$} \\
\hline Request & $\leq 2.2$ & - & $\geq 15$ & $\geq 6.5$ & $\leq 3.5$ & $\geq 130$ \\
\hline WBC W 2 & 0.77 & 4.9 & 13.6 & 6.15 & 1.0 & 88 \\
\hline $\mathrm{Y} / \mathrm{N}$ & $\mathrm{Y}$ & - & $\mathrm{N}$ (early) & $\mathrm{N}$ (early) & $\mathrm{Y}$ & $\mathrm{N}$ \\
\hline WBC W 1 & 1.4 & 1.4 & 5.6 & 2.87 & 1.8 & 41 \\
\hline $\mathrm{Y} / \mathrm{N}$ & $\mathrm{Y}$ & - & $\mathrm{N}$ & $\mathrm{N}$ & $\mathrm{Y}$ & $\mathrm{N}$ \\
\hline
\end{tabular}

\section{ASSESSMENT: A ROOM WITH DIFFERENT CONSTRUCTIONS - SIMULATION OF INDOOR OPERATIVE TEMPERATURES AND CORRELATION OF RESULTS WITH THE STANDARDS NBR 15775, NBR 15220 AND ISO 13786}

In the weather data file [6] used, temperatures hardly rise above $30^{\circ} \mathrm{C}$ but are above $26^{\circ} \mathrm{C}$ for 1,017 hours per year. That threshold can be used to assess the quality of indoor operative temperatures. In the case of a naturally ventilated building, indoor operative temperature cannot always be at low values, but all combinations of external and internal walls, ceiling and floor constructions that lead to 1,017 hours and fewer hours above $26^{\circ} \mathrm{C}$ have to be positively assessed, all others negatively.

The room described in Section 4 was simulated with PrimeroComfort software [7], an energy plus-based transient simulation. A typical output interface is shown in Fig. 5.

The results are summarized in Table 4 . A very strong influence of the chosen external wall construction on the resulting indoor operative temperature has to be noticed. Hereby two different groups have to be differentiated. The traditional architecture with wooden (light) ceilings forms the first group, and the contemporary architecture with concrete (heavy) ceilings forms the second group.

Now, all other conditions besides the construction of the external wall are identical in both groups. Differences in the number of hours above $26^{\circ} \mathrm{C}$ arise only from the effect of differences in the transfer of absorbed solar radiation through the wall. 


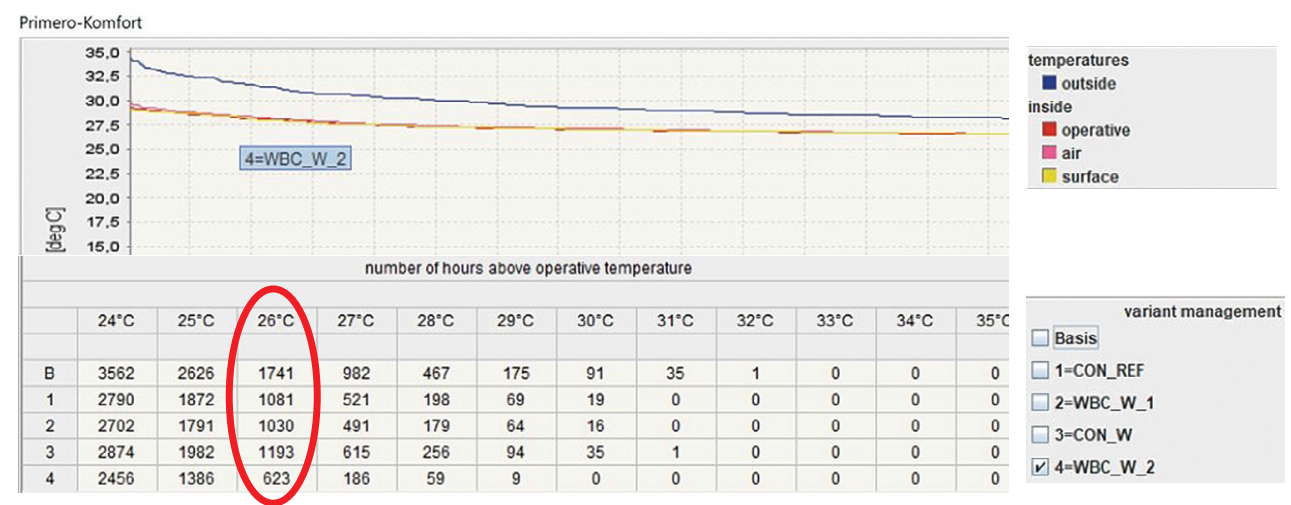

Figure 5: Output of PrimeroComfort software [7] showing the resulting indoor operative temperatures for different constructions as histograms (top) and as a table with hours above selected values (bottom). The used assessment threshold of $26^{\circ} \mathrm{C}$ is marked.

Table 4: Results of transient simulation of the selected room with different constructions number of hours where indoor operative temperature is above $26^{\circ} \mathrm{C}$

\begin{tabular}{ll}
\hline $\begin{array}{l}\text { Traditional Architecture } \\
\text { Ceiling and Floor: Wood Construction, Light. Internal Walls: Medium Massive (Brick, } \\
\text { Limestone) }\end{array}$ \\
\hline External Wall Construction & $\begin{array}{l}\text { Indoor Operative Temperature - Hours Above } \\
26^{\circ} \mathrm{C}\end{array}$ \\
\hline TRAD W (36 cm brick) & 667 \\
NBR W (18 cm brick) & 891 \\
\hline $\begin{array}{l}\text { Contemporary Architecture } \\
\text { Ceiling and Floor: Concrete Slabs, Heavy. Internal Walls: Medium Massive (Brick, Lime- } \\
\text { stone) }\end{array}$ & \\
\hline External Wall Construction & Indoor Operative Temperature - Hours Above \\
& $26^{\circ} \mathrm{C}$ \\
\hline CON W (10 cm concrete slab) & 1,193 \\
CON REF (hollow concrete element) & 1,081 \\
WBC W 1 (plywood with $5 \mathrm{~cm}$ air gap) & 1,030 \\
WBC W 2 (plywood with $5 \mathrm{~cm}$ mineral & 623 \\
fibre) & \\
CON W but without overhang 1.5 m & 1,741 \\
Fictive wall with very high TAD & 122 \\
\hline
\end{tabular}


The traditional construction behaves very well with $667 \mathrm{~h} / \mathrm{a}$ above $26^{\circ} \mathrm{C}$ and is far below the threshold of 1,017 h/a (outdoor temperature). Even the fictive traditional construction with a reduced thickness of bricks so that the recommendations of NBR 15220 are narrowly fulfilled, behaves well with $891 \mathrm{~h} / \mathrm{a}$. It can be concluded that the recommendations of NBR 15220 are acceptable and well set.

Both widely used contemporary constructions (CON W and CON REF) fulfil the obligatory NBR 15575 but do not fulfil the recommendations of NBR 15220. They do not reach the threshold of less than $1,017 \mathrm{~h} / \mathrm{a}$ above $26^{\circ} \mathrm{C}$.

The WBCs behave better, that already holds for the simple wall with two sheets of plywood and an air gap in between (WBC W 1), but it is still above 1,017 h/a. Only by filling the air gap with insulation (WBC W 2) a very good value of $623 \mathrm{~h} / \mathrm{a}$ is reached. The resulting operative temperatures in a period of two hot weeks are shown in Fig. 6. The difference between the constructions CON REF and WBC W 2 is about two degrees, especially in the peaks during the early afternoon.

Additionally, the resulting indoor operative temperature for a fictive construction with high TAD is shown and represents the maximal potential of optimizing the external wall construction.

It must be stated that the WBCs do not fulfil the obligatory NBR 15575 (because of the lack of mass!). But the improved WBC W 2 nearly fulfils the recommendations of NBR 15220 as well as of ISO 13786 for the dynamical thermal behaviour.

It can be concluded that the NBR 15575 refers exclusively to older traditional constructions where the desired thermal storage mass was concentrated in the walls. But that does not further correspond to contemporary architecture where the thermal storage mass is in the concrete slabs of the ceiling. The results of the simulation show well that this is completely sufficient and gives the freedom to replace the external walls with light construction. The requirements of NBR 15575 neglect that a good dynamical thermal behaviour can also be reached with thermal insulation and a low U-value.

Finally, the impact of a fictive wall with very high TAD $(36 \mathrm{~cm}$ brick plus $20 \mathrm{~cm}$ external insulation, $\mathrm{TAD}=829$ ) was simulated. It can be assumed that there is not any remaining heat transfer through the wall; consequently that would show the maximal potential of improving the external wall construction. The further reduction of indoor operative temperature is remarkable (see Fig. 6), but such constructions are very likely not an option in Brazil. Furthermore, it may be that the indoor atmosphere behind such a wall is already perceived as too cool.

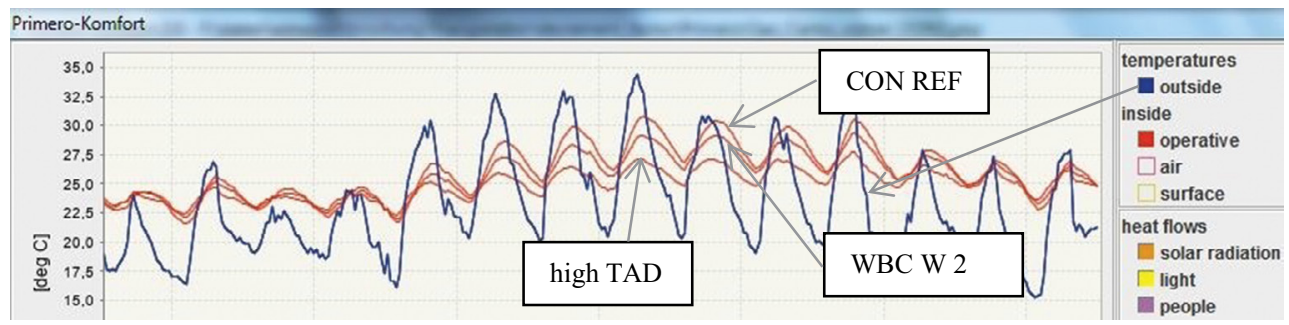

Figure 6: Output of PrimeroComfort software [7] showing indoor operative temperatures in a hot period of two weeks as well as outdoor temperature (blue line with stronger swing day-night) for two constructions. The wood-based construction WBC W 2 (two sheets of plywood with insulation inside) behaves much better (lower line) than the conventional construction CON REF with hollow concrete elements (upper line). The difference in operative indoor temperature is about two degrees. 


\section{DISCUSSION AND RECOMMENDATIONS FOR FUTURE STANDARDS}

Table 4 shows the result of another simulation, that of a room with construction CON W but without the overhang. The indoor operative temperature jumps from 1,193 to 1,793 hours above $26^{\circ} \mathrm{C}$, clearly showing the importance of shadowing the window as a first priority. Only then may a further reduction by improvement of the external wall construction have success. The depth of the overhang of $1.5 \mathrm{~m}$ fits very well to the depth of a standard balcony giving a good hint for architecture.

The present standards NBR 15575 and NBR 15220 do not represent all physical possibilities to reach a good comfort level. The calculation methods are too simple, with today's possibilities the standard should refer to ISO 13786 which describes the behaviour much better. That holds especially in regard to the transfer of heat through the wall, here $\mathrm{FS}_{0}$ is not applicable. Figure 7 confirms that there is (of course) no correlation to TAD, whereas the time lag $\varphi$ of NBR 15220 correlates roughly with decrement delay of ISO.
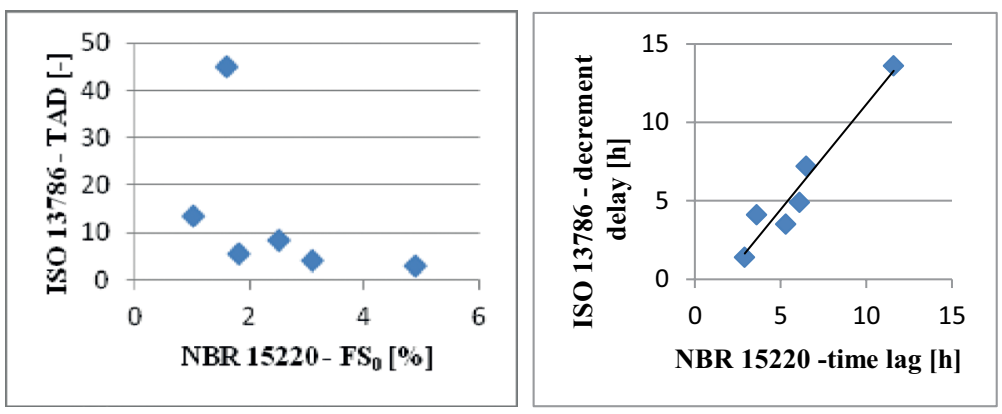

Figure 7: Comparison of the standards NBR 15220 and ISO 13786. The figures show with each point one of the simulated external wall constructions and their assessment by these standards. There is no correlation between $\mathrm{FS}_{0} / \mathrm{NBR} 15220$ and TAD/ISO 13786 (left) and a weak correlation between the time lag/NBR 15220 and decrement delay/ISO 13786 (right).

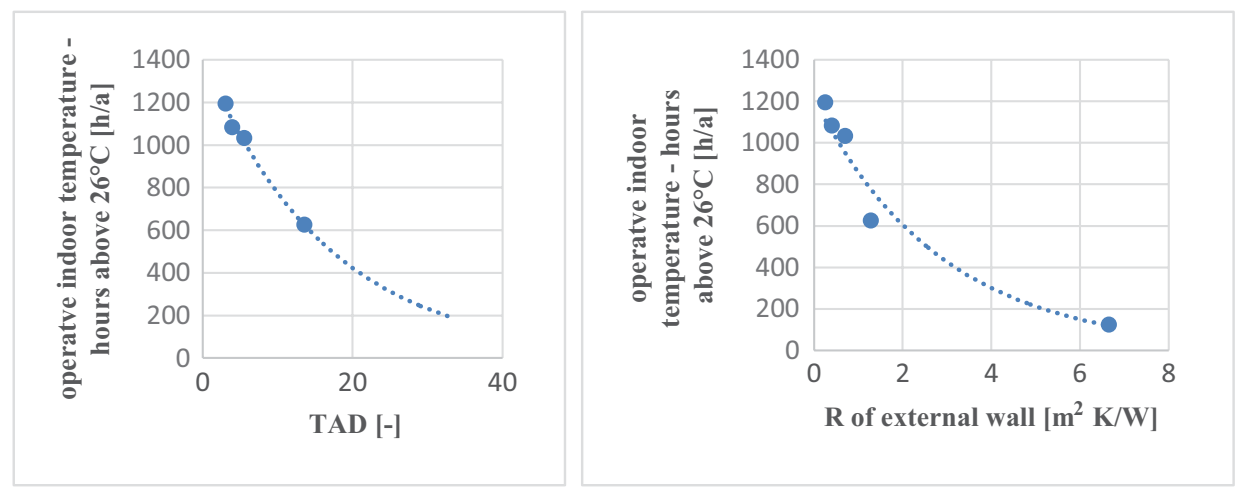

Figure 8: Correlation between the number of hours in indoor operative temperature and TAD/ISO 13786 (left) and $\mathrm{R}=1 / \mathrm{U}$ (right). Both correlations are good and confirm that ISO 13786 represents well the dynamic thermal behaviour of constructions and that thermal insulation is, besides thermal mass, a second way to reduce heat transfer through an external wall. 
Figure 8 (left) shows a good correlation between the hours in indoor operative temperature above $26^{\circ} \mathrm{C}$ and TAD/ISO 13786 including the tendency to still higher TAD (with the maximal potential of reduction down to $122 \mathrm{~h} / \mathrm{a}$ ). Figure 8 (right) shows the correlation between the hours in indoor operative temperature above $26^{\circ} \mathrm{C}$ and $\mathrm{R}=1 / \mathrm{U}$ of the external wall construction (with the minimal simulated "very high TAD" which has $\mathrm{U}=0.15 \mathrm{~W} / \mathrm{m}^{2} \mathrm{~K}$ ). The correlation is good and confirms that besides thermal mass, thermal insulation also protects an external wall against heat transfer of absorbed solar radiation.

Other investigations $[8,9]$ used different mathematical models for the physical behaviour but confirm also these conclusions.

\section{REFERENCES}

[1] http://www.concretecentre.com/Publications-Software/Design-tools-and-software/Dynamic-Thermal-Properties-Calculator-(1).aspx. Accessed on: 3 Oct. 2017

[2] http://nesa1.uni-siegen.de/mitarb/ehemalige/DissCompaore/Dissertation\%20Desire\%20Compaore.htm, (German PhD, see chapter 7). Accessed on: 3 Oct. 2017

[3] Dietrich, U. Tool available under udo.dietrich@hcu-hamburg.de, 2019

[4] https://www.abntcatalogo.com.br. Accessed on: 15 Nov. 2019

[5] Valdenebro Galaz, E.A.: Rethinking wood as a material of choice: thermal comfort analysis and simulation of multi-story housing with wood as an alternative construction material in Brazil, MA thesis, HafenCity University Hamburg, 2018

[6] https://energyplus.net/weather. Accessed on: 16 Nov. 2019

[7] http://www.primerosoftware.de/what-primero-english/. Accessed on: 16 Nov. 2019

[8] Larsen, S. F., Filippin, C., Lesino, G., Thermal behavior of building walls in summer: comparison of available analytical methods and experimental results for a case study. Building Simulation, 2, pp. 3-18, 2009

[9] Gagliano, A., Patania, F., Nocera, F., Signorello, C., Assessment of the dynamic thermal performance of massive buildings. Energy and Buildings, 72, pp. 361-370, 2014 